\title{
UPAYA MENINGKATKAN SOFT SKILL MAHASISWA MELALUI PEMBELAJARAN BERBASIS PROJECT DALAM MATA KULIAH BUSINESS PRACTICE
}

\author{
Murtianingsih \\ Dosen STIE Asia Malang
}

\begin{abstract}
:
The School of Economics of Asia is one of the universities that runs the education system. In the implementation of education system in STIE ASIA Malang using competency-based curriculum. Changes in global conditions with competition, job requirements and strategic change.

STIE ASIA as one of the universities in Indonesia where the results of a review of the curriculum offered to be able to compete with the strength of the work force of the ASEAN Economic Community (MEA) that has been implemented since January 1, 2016. With the orientation on the needs and relevance of the user then applied courses that are part of the local-based curriculum project "Business Practices".

Project-based learning enables students to learn which is a process whereby participants or students are self-clearing information through direct contact with others, working with groups, learning to be leaders, running a profit-oriented business, producing results in simple financial statements. Business Patterns, 2) Personal Selling, 3) Digital Marketing, 4) Business Functions. Meanwhile, soft skill as dependent variable is measured from communication ability, cooperation, confidence, and ability to be a leader.

Keywords: Professional Mindset, Personal Sales, Digital Marketing, Business Function, Soft Skill.

Abstrak:

Sekolah Tinggi Ilmu Ekonomi Asia adalah salah satu perguruan tinggi yang menyelenggarakan sistem pendidikan tersebut. Dalam pelaksanaan sistem pendidikan di STIE ASIA Malang menggunakan kurikulum berbasis kompetensi. Perubahan kondisi global dengan adanya persaingan, persyaratan kerja dan perubahan orientasi diperlukan peningkatan mutu outcome melalui perubahan prilaku pembelajaran.

STIE ASIA sebagai salah satu Perguruan Tinggi di Indonesia yang mencetak outcome melakukan pengkajian ulang terhadap kurikulum yang ditawarkan agar lulusan yang dihasilkan mampu bersaing dengan kompetensi tenaga kerja asing sebagai dampak dari Masyarakat Ekonomi ASEAN (MEA) yang sudah diterapkan sejak 1 Januari 2016. Dengan berorientasi pada kebutuhan dan relevansi pengguna maka diterapkan mata kuliah yang merupakan bagian dari kurikulum kelokalan yaitu berbasis project "Business Practice".

Pembelajaran berbasis project membuat mahasiswa mengalami pembelajaran yang bermakna yaitu suatu proses dimana peserta atau mahasiswa menggali sendiri informasi malalui aktivitas langsung presentasi kepada pihak lain, bekerja dengan kelompok, belajar menjadi leader, menjalankan aktivitas bisnis yang berorientasi pada benefit, membuat dan melaporkan hasil kerja dalam laporan keuangan sederhana. Business Practice sebagai pembelajaran berbasis project diukur dengan menggunakan empat model yang dalam penelitian ini juga sebagai variabel independent yaitu meliputi : 1) Profesional Mindset, 2) Personal Selling, 3) Digital Marketing, 4) Business Function. Sementara itu soft skill sebagai variabel dependen diukur dari kemampuan komunikasi, bekerjasama, percaya diri, dan kemampuan menjadi leader.

Keyword : Profesional Mindset, Personal Selling, Digital Marketing, Business Function, Soft Skill.
\end{abstract}

\section{PENDAHULUAN}

Perubahan kondisi global dengan adanya persaingan, persyaratan kerja dan perubahan orientasi diperlukan peningkatan mutu outcome melalui perubahan prilaku pembelajaran. Dalam kegiatan nyata proses pembelajaran perlu diperhatikan situasi pembelajaran dan evaluasi, sehingga mahasiswa memiliki pemahaman yang utuh dari sebuah pembelajaran tidak hanya tahu (know) namun juga bisa melakukan (to do).

Rendahnya daya serap tenaga kerja pada sektor riil menjadikan angka pengangguran setiap tahunnya selalu bertambah, Lulusan Perguruan
Tinggi mengalami dilema karena selain sulit terserap dalam dunia kerja nasional juga menghadapi persaingan pasar kerja dengan tenaga kerja asing dari negara-negara ASEAN sebagai dampak berlakunya Masyarakat Ekonomi ASEAN (MEA) sejak 1 Januari 2016. Hal ini terjadi karena kualifikasi yang dibutuhkan oleh pengguna tidak sesuai dengan kemampuan yang dimiliki oleh tenaga kerja. STIE ASIA sebagai salah satu Perguruan Tinggi di Indonesia yang mencetak outcome melakukan pengkajian ulang terhadap kurikulum yang ditawarkan. Dengan berorientasi pada kebutuhan dan relevansi pengguna maka diterapkan mata kuliah 
yang merupakan bagian dari kurikulum kelokalan yaitu berbasis project "Business Practice".

Pembelajaran berbasis project "Business Practice" membuat mahasiswa mengalami pembelajaran yang bermakna yaitu suatu proses dimana peserta atau mahasiswa menggali sendiri informasi malalui aktivitas langsung presentasi kepada pihak lain, bekerja dengan kelompok, belajar menjadi leader, menjalankan aktivitas bisnis yang berorientasi pada benefit, membuat dan melaporkan hasil kerja dalam laporan keuangan sederhana. Dari aktivitas riil yang dilakukan tersebut diharapkan mahasiswa mendapat pemahaman soft skill yang optimal melalui pembentukan habit dan karakter yang berkelanjutan yaitu pembelajaran berbasis project diberikan dari semester pertama sampai keempat, sehingga mereka tidak hanya mampu secara hard skill namun juga mempunyai soft skill yang relevan dengan kebutuhan pengguna saat ini.

Diana Curtis (2006) dalam risetnya menyatakan bahwa : enthusiasm alone isn't enough of a justification to advocate project-based learning, but the result of that enthuasism argue in its favor. Sedangkan Neumont University (2006) menyatakan bahwa : research show that we retain significantly more of what we learn when we learn by doing or from teaching others than we retain when we learn from lecture or from reading. Berdasarkan hal tersebut maka penelitian ini mengambil judul yaitu Upaya Meningkatkan Soft Skill Mahasiswa Melalui Model Pembelajaran Berbasis Project Dalam Mata Kuliah "Business Practice".

\section{TINJAUAN PUSTAKA}

\section{Landasan Teori}

\section{Teacher Center Learning Method}

Model pembelajaran teacher center learning merupakan metode yang konvensional, dimana pengajar dianggap sebagai seorang yang paling menguasai materi dan semua informasi diberikan kepada peserta didiknya melalui ceramah (lecturing) yang bersifat satu arah dan transfer informasi. Kondisi kelas juga individual dan aspek penilaian lebih pada hasil tanpa melihat pada proses, metode ini sangat stagnan dan peserta didik hanya mengetahui (to know) tanpa ada proses dan aktivitas riil yang dilakukan (to do) sehingga pengajar yang semakin cerdas sementara peserta hanya memiliki pengalaman mendengar paparan saja (http://new-view.info/neweducationaltechnology. diakses pada Mei 2016 )

2. Student Center Learning Method

Student Center Learning merupakan proses pembelajaran yang melibatkan siswa secara aktif dan proses pembelajaran berpusat pada siswa, diharapkan siswa dapat secara aktif terlibat dalam membangun pengetahuan, sikap, dan prilaku. Melalui proses pembelajaran yang keterlibatan siswa secara aktif, berarti guru tidak lagi mengambil hak seorang peserta didik untuk belajar

(http://amdayhary.blogspot.co.id/2014/04/model -pembelajaran-teacher-center-dan.html)

\section{Project Based Learning}

Menurut Bell (1995:28) Project Based Learning merupakan pendekatan pembelajaran yang memberikan kebebasan kepada peserta didik untuk merencanakan aktivitas belajar, melaksanakan proyek secara kolaboratif, dan pada akhirnya menghasilkan produk kerja yang dapat dipresentasikan kepada orang lain.

\section{Soft Skill}

Soft skill merupakan kemampuan, bakat, atau ketrampilan yang ada di diri manusia yang dilakukan secara non teknis artinya tidak terbentuk atau tidak terlihat wujudnya yang dapat dikatakan sebagai ketrampilan personal, misalnya kepercayaan diri, pengendalian emosi, mampu bekerjasama dengan orang lain (Ardiansyah, Reza, Blogspot, 2010/9).

\section{Kerangka Konseptual}

\section{Gambar 2.1 Kerangka Konseptual}

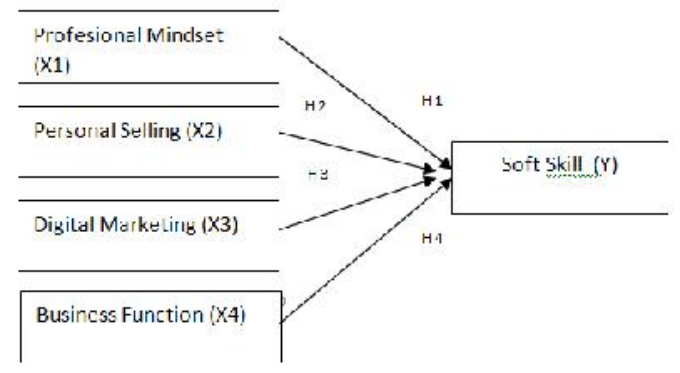

\section{METODE PENELITIAN}

Tujuan Penelitian

Berdasarkan rumusan masalah diatas maka penelitian ini bertujuan untuk memberikan bukti riil apakah pembelajaran berbasis project "Business Practice" dapat meningkatkan soft skill mahasiswa STIE ASIA. Hal ini akan dibuktikan melalui uji hipotesis dengan menyebarkan kuisioner pada mahasiswa aktif yang menempuh mata kuliah tersebut, hasil yang akan diperoleh nanti sifatnya adalah persepsi mahasiswa STIE ASIA Malang.

\section{Jenis dan Sumber Data penelitian}

Jenis data yang digunakan dalam penelitian ini adalah data kuantitatif. Data kuantitaif merupakan data yang berbentuk angka atau bilangan yang dapat 
diolah dan dianalisa menggunakan rumus matematika maupun statistika.

Sumber data yang digunakan merupakan sumber data primer yang diperoleh melalui penyebaran kuesioner kepada mahasiswa STIE ASIA Malang yang sudah menempuh mata kuliah Business Practice.

\section{Metode pengumpulan data}

Metode Pengumpulan data yang digunakan dalam penelitian ini melalui penyebaran kuesioner kepada subjek yang diteliti yaitu mahasiswa STIE ASIA yang sudah menempuh mata kuliah Business Practice. Kuesioner yang disebarkan berisi pertanyaan dan pernyataan tertulis yang didesain sedemikian rupa sehingga tidak menimbulkan keraguan bagi responden yang dimintai pendapatnya.

\section{Definisi Operasional variabel}

a. Variabel independen (X1) dalam penelitian ini adalah implementasi profesional mindset yang meliputi : 1. Project business berorientasi pada profit. 2. Project business dijalankan secara tim. 3. Project business membutuhkan perencanaan yang matang. 4. Project business memiliki daya tarik dan daya saing

b. Variabel independen (X2) dalam penelitian ini adalah Personal Selling yang meliputi : 1 . Personal selling dilakukan secara tim. 2. Personal selling membutuhkan kemampuan komunikasi. 3. Personal selling membutuhkan perencanaan dan trik khusus. 4. Personal selling sangat efektif dalam aktivitas bisnis

c. Variabel independen (X3) dalam penelitian ini adalah Digital Marketing yang meliputi : 1 . Pemasaran melalui media sosial lebih efektif. 2. Pemasaran secara on line dapat mencapai target. 3. Produk lebih cepat dikenal publik melalui media social. 4. Pemasaran on line sangat menunjang bisnis

d. Variabel independen (X4) dalam penelitian ini adalah Business function (SDM, Operational, Keuangan, pemasaran) yang meliputi : 1. Bisnis dijalankan dengan kejujuran dan perencanaan yang matang. 2. Laporan keuangan sangat diperlukan dalam bisnis. 3. Kemampuan memanage orang sangat perlu dalam bisnis. 4 . Bisnis harus mempunyai jaringan pemasaran

Variabel terikat (variabel dependent / Y). Variabel terikat dalam penelitian ini adalah soft skill (Y) yang meliputi : 1. kemampuan komunikasi. 2. Rasa percaya diri. 3. Belajar bekerjasama. 4. Belajar menjadi leader yang baik

\section{HASIL YANG DICAPAI}

\section{Statistic Diskriptif}

Berdasarkan data descriptive statistic iperoleh hasil dalam tabel sebagai berikut.

Tabel 1. Descriptive Statistics

\section{Descriptive Statistics}

\begin{tabular}{|l|l|r|r|}
\hline & Nean & Std. Deviation & \multicolumn{1}{c|}{ N } \\
\hline SoftSkill & 17.8253 & .67688 & 269 \\
Profesional Mindset & 16.2639 & 1.19742 & 269 \\
Personal Selling & 17.0186 & .89964 & 269 \\
Digital Marketing & 17.0743 & .82524 & 269 \\
Business Function & 16.7807 & .85532 & 269 \\
\hline
\end{tabular}

Nilai rata-rata dari variabel yang diteliti melalui kuisioner yang disebarkan kepada 269 mahasiswa aktif sebagai responden (sample penelitian) yang mengacu pada Isaac Michael dengan taraf signifikasi $5 \%$ berada pada kisaran nilai 16,2639 - 17,8253 dari 4 indikator yang digunakan untuk mengukur setiap variabel dengan skala linkert 1-5 yang menandakan bahwa rata-rata mehasiswa menyatakan setuju terhadap indikator yang digunakan untuk mengukur variabel penelitian ini.

\section{Uji Validitas dan Reliabilitas Uji Validitas}

Uji Validitas dilakukan dengan tujuan bahwa kuisioer yang diberikan kepada responden memiliki tingkat validitas sesuai dengan jumlah sample yang digunakan, dengan mengacu pada nilai $r$ hitung $>$ dari r table pada signifikansi 5\% pada jumlah sample 269 mahasiswa ( $\mathrm{r}$ table sebesar 0,138 ) yaitu bahwa item pertanyaan yang digunakan sebagai indikator dalam pengukuran variabel memiliki korelasi signifikan terhadap skor totalnya (VALID).

Tabel 2. Hasil uji validitas untuk variabel independen

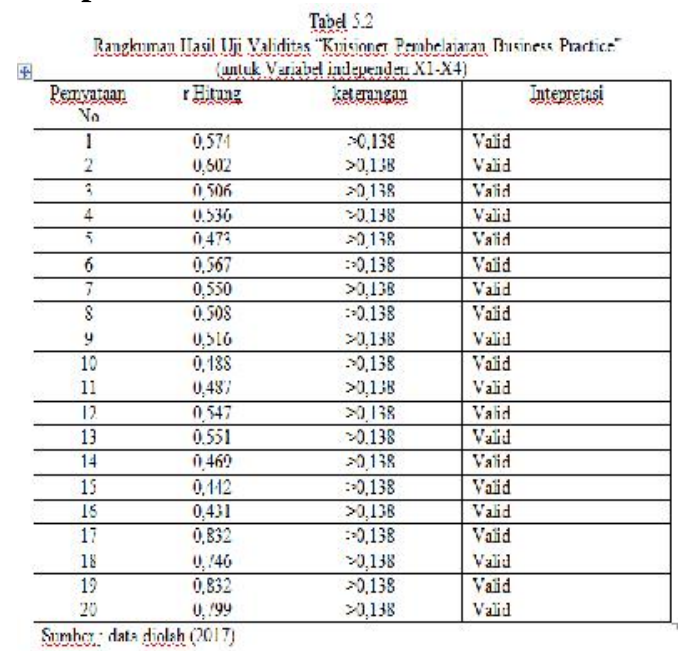


Tabel 4. Rangkuman Hasil Uji Validitas "Kuisioner Pembelajaran Business Practice"(untuk Variabel dependen Y)

\begin{tabular}{|c|c|cl|}
\hline $\begin{array}{c}\text { Penyataar } \\
\mathrm{N}_{0}\end{array}$ & r Hiturg & keterangan & Interpetasi \\
\hline 17 & 0,832 & $>0,138$ & Valid \\
\hline 18 & 0,746 & $>0,138$ & Valid \\
\hline 19 & 0,832 & $>0,138$ & Valid \\
\hline 20 & 0,799 & $>0,138$ & Valid \\
\hline
\end{tabular}

Sumber : data diolah (2017)

\section{Uji Reliabilitas}

Berdasarkan nilai cronbach alpha baik variabel independen (X) maupun variabel dependen (Y) > 0,70 yang menyatakan bahwa pernyataan yang digunakan dalam kuisioner memenuhi syarat relibilitas.

\section{Uji Asumsi Klasik}

\section{a. Uji Normalitas}

Berdasarkan hasil uji normalitas nilai Kolmogorov Smirnov untuk variabel independen yaitu professional mindset (X1), Personal Selling (X2), Digital Marketing (X3), Business Function (X4), dan variabel dependen soft skill (Y) memiliki nilai $>0,05$ dinyatakan data berdistribusi normal.

\section{b. Uji Heterokedastisitas}

Dari output correlation 2 tailed di dapat nilai korelasi dari empat variabel independen dengan unstandardized residual lebih dari 0,05. Karena nilai signifikansi lebih dari 0,05 maka dinyatakan bahwa tidak terjadi heterokedastisitas pada model.

\section{c. Uji Multikolinieritas}

Berdasarkan hasil uji didapat hasil empat variabel memiliki nilai tolerance lebih besar dari 0,10 dan nilai VIF kurang dari 10 maka disimpulkan bahwa tidak terjadi multikolinieritas.

\section{d. Uji Autokorelasi}

Uji autokorelasi dengan melihat nilai Durbin Watson yaitu apabila nilai DW berada pada rentang DU < DW < 4-DU yaitu 1,881 < 1,995 < 4-1,861, sehingga dinyatakan bebas autokorelasi.

\section{Hasil Uji Hipotesis}

Hasil output spss seperti yang terdapat pada table 5.10 menyatakan bahwa model regresi adalah sebagai berikut :

$\mathrm{Y}=10,060+0,68 \mathrm{X} 1+0,105 \mathrm{X} 2+0,200 \mathrm{X} 3+0$, $88 \times 4$

Model tersebut menggambarkan bahwa business practice memberikan dampak terhadap peningkatan soft skill mahasiswa yaitu :

Mahasiswa STIE ASIA memiliki soft skill sebesar 10,060 apabila factor lain bernilai 0 , hal ini menandakan bahwa sebenarnya mahasiswa secara rata-rata sudah memiliki soft skill namun belum optimal masih bisa di dukung oleh factor lain. Profesional Mindset (X1) sebesar 0,68 menandakan bahwa varibel ini mampu memberikan pengaruh sebesar $68 \%$ terhadap peningkatan soft skill mahasiswa dan apabila factor lain bernilai 0 . Sedangkan personal selling (X2) memberikan dampak sebesar $10,5 \%$ terhadap peningkatan soft skill mahasiswa apabila factor lain juga 0 . Digital marketing mampu memberikan pengaruh sebesar $20 \%$ terhadap peningkatan soft skill mahasiswa, business function juga mampu memberikan pengaruh terhadap peningkatan soft skill mahasiswa sebesar 88 $\%$ dan factor yang paling besar pengaruhnya sebagai salah satu project business practice terhadap peningkatan kualitas soft skill mahasiswa.

\section{KESIMPULAN DAN SARAN}

Kesimpulan

Berdasarkan pembahasan diperoleh beberapa kesimpulan dari hasil penelitian ini, yaitu :

1. Profesional Mindset dapat meningkatkan soft skill mahasiswa melalui project bisnis yang berorientasi profit / benefit dengan menggunakan perencanaan yang matang. Perencanaan ini dikaitkan dengan permodalan awal yang dijalankan, anggota atau tim memahami bahwa bagaimana project bisnis bisa memperoleh keuntungan sehingga dapat sustainable.

2. Personal selling, sejalan dengan variabel professional mindset yaitu mahasiswa melalui kegiatan personal selling secara langsung kemampuan komunikasi lebih baik dan perencanaan bisnis yang dilakukan brsama dengan tim dapat mencapai target yang ditentukan di awal.

3. Digital marketing; pembelajaran berbasis project yang memberikan arahan bahwa bisnis yang profit oriented bisa dilakukan dengan pemanfaatan teknologi sebagai sarana marketing. Pembelajaran digital marketing juga memberikan kontribusi terhadap peningkatan soft skill mahasiswa melalui pemahaman bahwa media social juga sebagai sarana untuk menjadikan produk atau usaha menjadi dikenal oleh public.

4. Business function yang merupakan variabel keempat dalam penelitian ini juga menunjukan hasil positif terhadap peningkatan soft skill mahasiswa yakni pengaetahuan memanage dan mengoperasikan usaha dengan initial capital yang diberikan dapat dikelola dengan baik untuk dapat menghasilkan keuntungan usaha.

\section{Keterbatasan dan saran}

Adapun keterbatasan dalam penelitian ini adalah indikator yang digunakan untuk mengukur soft skill 
melalui empat varibel : professional mindset, personal selling, digital marketing, business function hanya menggunakan bebrapa indikator seperti terirai dalam definisi operasional variabel. Untuk penyempurnaan konsep model pembelajaran selanjutnya perlu di ukur dari indikator yang berbeda yang belum ada dalam penelitian ini, antara lain pengendalian resiko binis, dan bagaimana memperluas jaringan bisnis melalui kemampuan social.

\section{DAFTAR PUSTAKA}

1. PP No 60 Tahun 1999tentang Tujuan pendidikan Tinggi

2. UU No 12 tahun 2012 tentang pendidikan Tinggi

3. Bell, B. F (1995), Children's Science. Constructivism and Learning In Science Victoria : Deakin University Pers.

4. Curtis, D. (2006) Start With Pyramid. Diambil pada $10 \quad$ Januari 2016 dari http://www.edutopia.org
5. Global School Net (2000). Introduction to Network Project Based Learning. Diambil pada 12 Januari $2016 \quad$ dari http://www.gsn.org/web/pbl/whatis.htm

6. Neumont University. (2006). Project Based Learning. Diambil pada 10 Januari 2016 dari http://www.neumont.edu/futurestudents/bachelor.project-based-learning.html

7. Sugiyono. 2011. Metode Penelitian Kuantitatif, Kualitatif dan R\&D. Bandung. Alfabeta.

8. Trihendradi, Cornelius, 2013. Step By Step IBM SPSS 21: Analisis Data Statistik. Yogyakarta : Penerbit Andi

9. http://new-view.info/neweducationaltechnology./benefits-of.teacher-centeredlearning.html

10. http://amdayhary.blogspot.co.id/2014/04/modelpembelajaran-teacher-center-dan.html 